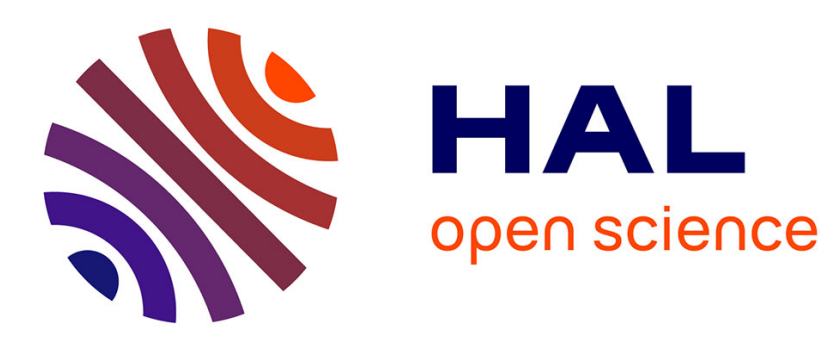

\title{
Dynamic model of magnetic materials applied on soft ferrites
}

Pierre Tenant, Jean-Jacques Rousseau

\section{To cite this version:}

Pierre Tenant, Jean-Jacques Rousseau. Dynamic model of magnetic materials applied on soft ferrites. IEEE Transactions on Power Electronics, 1998, 13 (2), pp.372-379. hal-00141594

\section{HAL Id: hal-00141594 \\ https://hal.science/hal-00141594}

Submitted on 23 Apr 2007

HAL is a multi-disciplinary open access archive for the deposit and dissemination of scientific research documents, whether they are published or not. The documents may come from teaching and research institutions in France or abroad, or from public or private research centers.
L'archive ouverte pluridisciplinaire HAL, est destinée au dépôt et à la diffusion de documents scientifiques de niveau recherche, publiés ou non, émanant des établissements d'enseignement et de recherche français ou étrangers, des laboratoires publics ou privés. 


\title{
Dynamic Model of Magnetic Materials Applied on Soft Ferrites
}

\author{
P. Tenant and J. J. Rousseau
}

\begin{abstract}
A behavioral model of magnetic materials is presented. This model takes into account both hysteresis and dynamic phenomena. It predicts $B(H), \varphi(t)$, and $d \varphi(t) / d t$ characteristics, and a few pieces of experimental data are needed to identify its parameters. In this paper, the authors propose to validate the model for some typical applications encountered in power electronics. Results obtained are very satisfactory.
\end{abstract}

Index Terms - Core losses, dynamic effect, hysteresis, inductor, soft ferrites, transformer.

\section{INTRODUCTION}

D URING the last few years in the field of power electronics, improvements in switching devices and power converter topologies have enabled important increases in switching frequencies. These recent advances have allowed major reductions of cost, weight, and volume of magnetic components such as inductors and transformers. On the other hand, high switching frequencies have brought new difficulties concerning the design of magnetic components. It is the same for the computer-aided design (CAD) tools development. The increase in frequency requires taking into account a lot of phenomena which are negligible at lower frequencies. The decrease in volume imposes to better take into account thermal problems. That means that magnetic components designers need thermal model to evaluate the temperature in few points. Both iron and copper losses constitute essential data for any thermal model. Unfortunately, losses are not easy to accurately determine. Copper losses calculation requires considering both skin and proximity effects. For magnetic components with air gap, additional losses are due to the leakage flux, which cause eddy currents in conductors. Core losses calculation in magnetic material are also difficult. In power electronics, operating conditions are specific. In most cases, flux densities are triangular or trapezoidal.

For inductors, an important de level is observed. However, ferrite manufacturers only give losses for sinusoidal-applied flux densities. Moreover, CAD tools in power electronics require fast, simple, and easy-to-use models in order to calculate waveforms. A magnetic component is one component in a converter. So, simple methods must be used to model it. It is a difficult task. Magnetic characteristics are nonlinear because of hysteresis phenomena and time dependent because of dynamic

Manuscript received December 23, 1995; revised January 29, 1997. Recommended by Associate Fditor, W. J. Sarjeant. This work was supported by the French Minister of Research and Space and Shneider-Electric.

The authors are with CEGELY-ECPA-INSA de LYON, 69621, Villeurbanne, Cedex, France (e-mail: rousseau(a cegely.insa-lyon.fr).

Publisher Item Identifier S 0885-8993(98)01940-1. effects such as eddy currents. The temperature must be taken into account, and the model must also consider air gap and windings.

Magnetic properties modeling is a first important step of magnetic component modeling. We are working on a behavioral model for the predetermination of electrical and magnetic characteristics. This model takes into account hysteresis and dynamic phenomena. Initially applied on $\mathrm{FeSi}$ and $\mathrm{FeNi}$ materials, its application has been extended to soft ferrites.

The purpose of this article is to present the performance of this model. In Section II, the model is briefly described. In Section III, identification model parameters are presented in the specific case of soft ferrites. In Section IV, the model is validated for some typical applications encountered in power electronics.

\section{The Behavioral Model}

We only consider toroid circuits, without air gap. However, the principles of the model can be easily extended to other geometries, including air gaps. We assume that both the flux density $B$ and the magnetic field $H$ are uniforms throughout the material. We also assume that the temperature is constant. The parameters of the model are then identified for a given temperature. The base of the model is the following: the real magnetic circuit is replaced by a fictitious equivalent circuit of the same geometry without any dynamic properties [1]. These dynamic properties are represented by an additional winding of $n$ turns closed on a resistor $r$ (Fig. 1).

The Ampere's law applied to this equivalent circuit of effective length $l_{e}$ gives

$$
H \cdot l_{e}=N \cdot I_{\text {app }}+n \cdot I_{\text {ind }} .
$$

We can define the current $I$ by

$$
H \cdot l_{e}=N \cdot I .
$$

Equation (2) is relative to a material without any dynamic properties. Its magnetic properties correspond to a strictly static behavior. So, we can state

$$
\varphi=F(I)
$$

where $\varphi$ is the flux in cross-sectional area.

Equation (3) is graphically illustrated by all the static magnetic characteristics of the material. The current $I_{\text {ind }}$ flowing the fictitious winding is defined by

$$
I_{\text {ind }}=\frac{e}{r}=-\frac{n}{r} \cdot \frac{d \varphi}{d t} .
$$




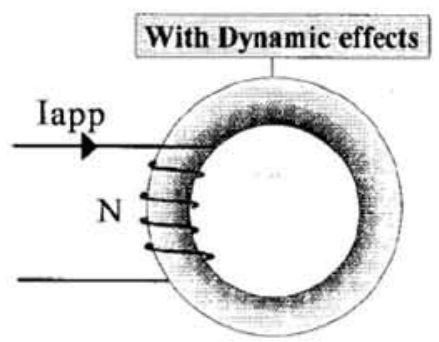

(a)

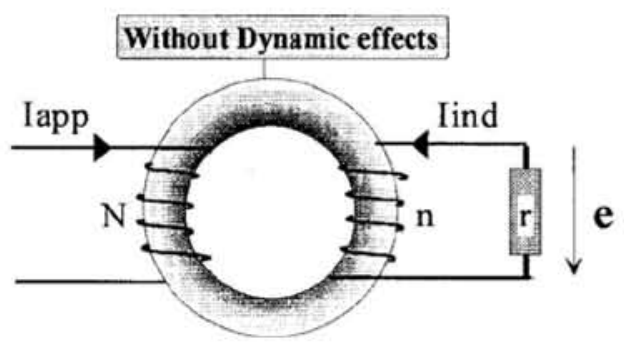

(b)

Fig. 1. Principle of the model: (a) the real magnetic circuit is replaced by a (b) fictitious equivalent circuit of the same geometry without any dynamic properties. Dynamic properties are represented by a additional winding of $n$ turns closed on a resistor $r$.

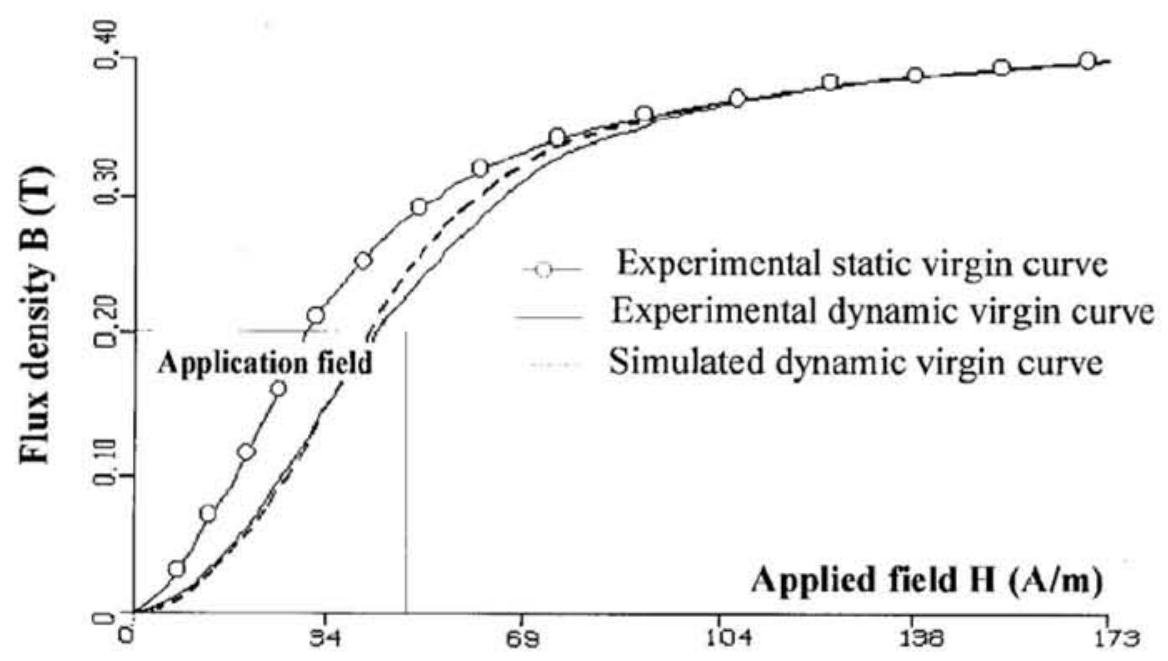

Fig. 2. Identification of the parameter $\gamma$ in the field of application of the material, which is between the range $100-200 \mathrm{mT}$.

Substituting (4) in (1)

$$
H \cdot l_{e}=N \cdot I_{\text {app }}-\frac{n^{2}}{r} \cdot \frac{d \varphi}{d t} .
$$

Stating $\gamma=n^{2} / r$ and substituting (2) in (5), we finally obtained the following equation linking the applied current $I_{\text {app }}$ to the flux $\varphi$ :

$$
\frac{d \varphi}{d t}=\frac{N}{\gamma} \cdot\left[I_{\text {app }}-F^{-1}(\varphi)\right] .
$$

To solve this equation, it is necessary to identify both the coefficient $\gamma$, assumed to be constant, representative of the dynamic behavior of the sample, and the relation $I=F^{-1}(\varphi)$, which characterizes the hysteresis phenomena.

\section{IDENTIFICATION OF THE MODEL PARAMETERS}

\section{A. Identification of the Parameter $\gamma$}

In order to identify the parameter $\gamma$, the static virgin curve and one of the dynamic virgin curves are required [2]. The experimental dynamic virgin curve is used as a reference. The correct value of the parameter $\gamma$ is obtained when the following error criterion is minimized:

$$
\varepsilon=\frac{\int_{0}^{H \max }\left(B_{\text {measured }}-B_{\text {Simulated }}\right) d H}{\int_{0}^{H \max } B_{\text {measured }} d H} .
$$

When this criterion is minimum, the parameter $\gamma$ is correctly estimated. Peak flux density generally observed in power electronic applications is in the range $50-300 \mathrm{mT}$. So, it is not useful to apply the criterion until saturation. Particularly, this criterion must be minimized in the field of application of the material. Fig. 2 concerns a magnetic material whose field of application is between 100-200 $\mathrm{mT}$. The parameter $\gamma$ has been set so that the criterion is minimum in the field 0-200 $\mathrm{mT}$. Measurements have been carried out with different ring cores in order to study the variation of the $\gamma$ parameter versus core sizes. The same value of this parameter has been obtained. That means this parameter characterizes dynamic effects for a given material. No dimension effect has been shown. Nevertheless it would be advisable to limit these conclusions for small cores (diameter less than $30 \mathrm{~mm}$ ). For important dimensions, no measurement has been carried out. For this study, the $\gamma$ parameter is kept constant for a given material.

\section{B. Identification of the Inverse Static Function $I=F^{-1}(\varphi)$}

The inverse static function $I=F^{-1}(\varphi)$ characterizes the static behavior of the material, i.e., the hysteresis phenomena. According to the considered application, static hysteresis loops can be symmetric or non. So, it is necessary to have a hysteresis model, which generates any type of static hysteresis loops. Currently, two models are often used: the Jiles and 


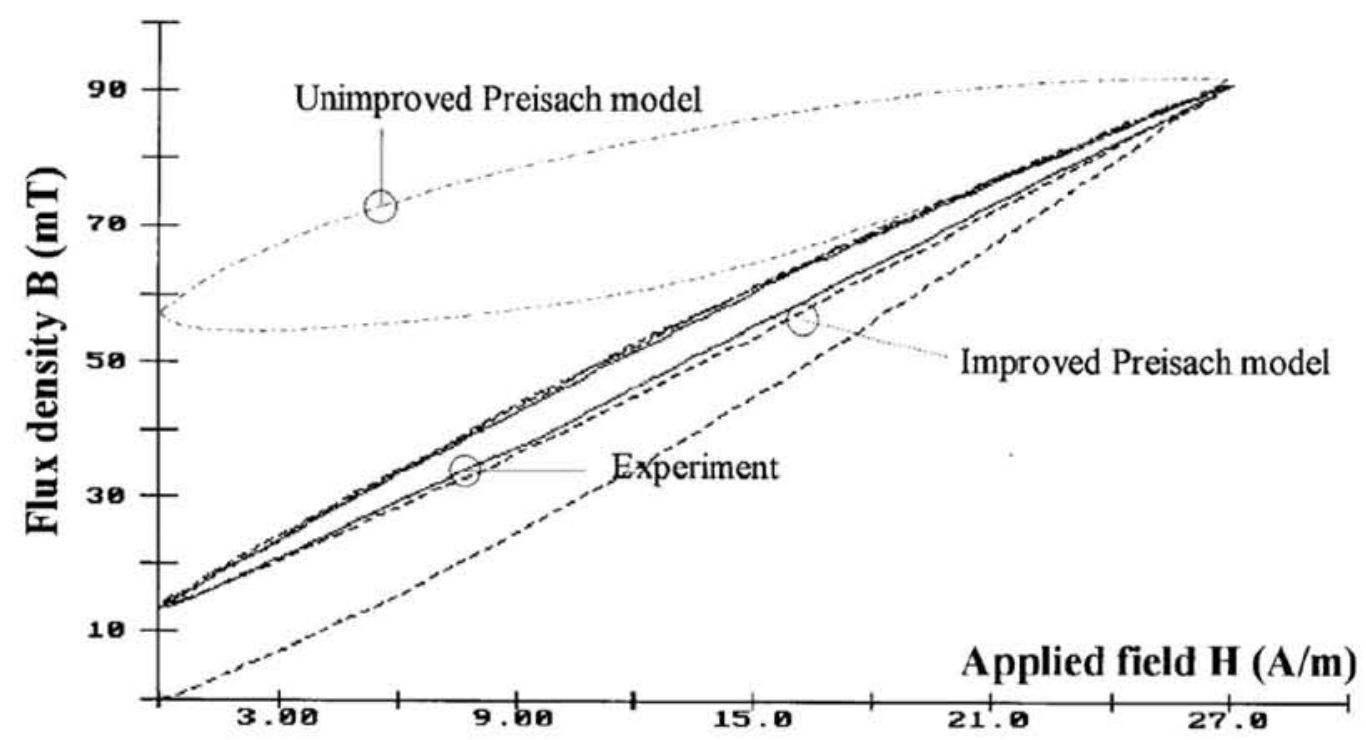

Fig. 3. Illustration of improvements brought by the deviation model. Comparison between simulated and measured minor loops obtained with a rectified sinusoidal magnetic field $H$ of $10-\mathrm{Hz}$ frequency and $27-\mathrm{A} / \mathrm{m}$ magnitude.

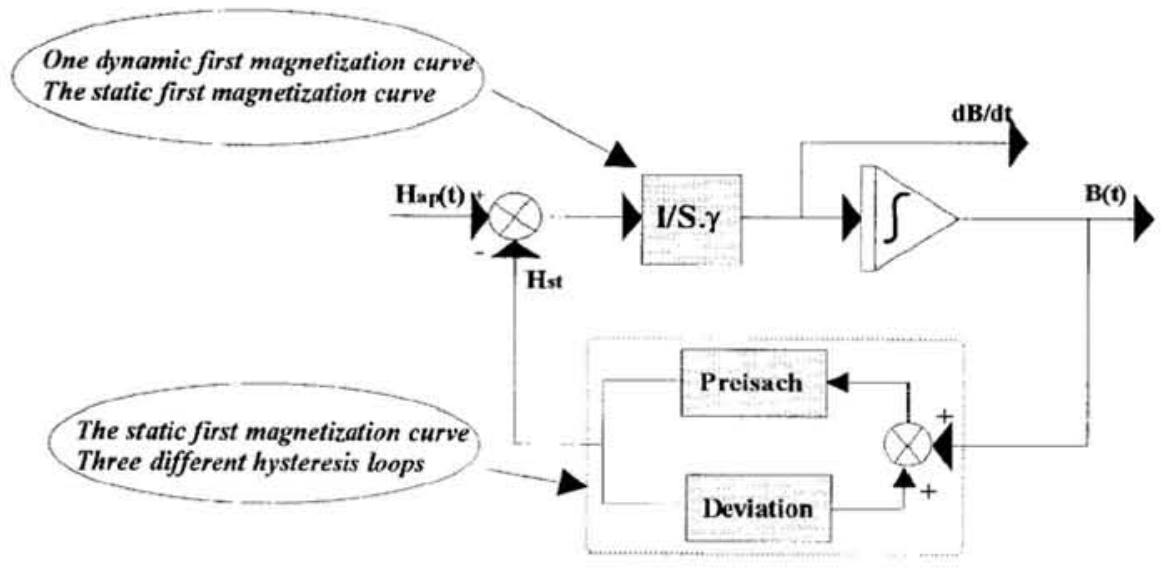

Fig. 4. Dynamic model and required experimental results.

Atherton model [3], [4] and Preisach model [5]. The Preisach model has been chosen for its great simplicity. It allows the generation of all static magnetic characteristics without major difficulties, and its parameters can be easily identified. Amongst numerous identification techniques that can be used to identify the Preisach model parameters [6]-[9], a simple method has been used. This is the method proposed by Biorci and Pescetti [7]. Unfortunately, and particularly when the Biorci and Pescetti identification technique is used, the Preisach model has important shortcomings [10]. The Preisach model is very accurate when peak flux density is close to saturation, either for major loops or for minor loops. Unfortunately, it considerably deteriorates when peak flux density is far from saturation. Hysteresis losses are overestimated.

Classical solutions proposed to improve the Preisach model have been tested [11]-[17]. But these solutions are not really adapted to the context of power electronics and results obtained are unsatisfactory. Consequently, a new method has been developed in order to improve significantly the Preisach model. This method is based on the prediction of the deviations observed between simulation and experiment. It has been shown that deviation characteristics can be easily interpolated using very simple laws (parabolas and straight lines). Only the knowledge of the remanence versus the peak flux density of symmetrical loops is sufficient. Improvements brought to the Preisach model are very good. In Fig. 3, a comparison between simulation and experiment is presented. The applied field is sinusoidal, rectified, and of a $10-\mathrm{Hz}$ frequency. One can see that the predicted hysteresis loop is in accordance with experimental data. In this figure, only static hysteresis loops are compared because the first magnetization curve do not set problem. Both the Preisach model and the improved Preisach model compute very well the first magnetization curve (the first magnetization curve is one of the two experimental curves which are required to calculate the Preisach function).

\section{Set of Experimental Results}

Fig. 4 shows the presented dynamic model and specifies the set of experimental results which are required to generate 


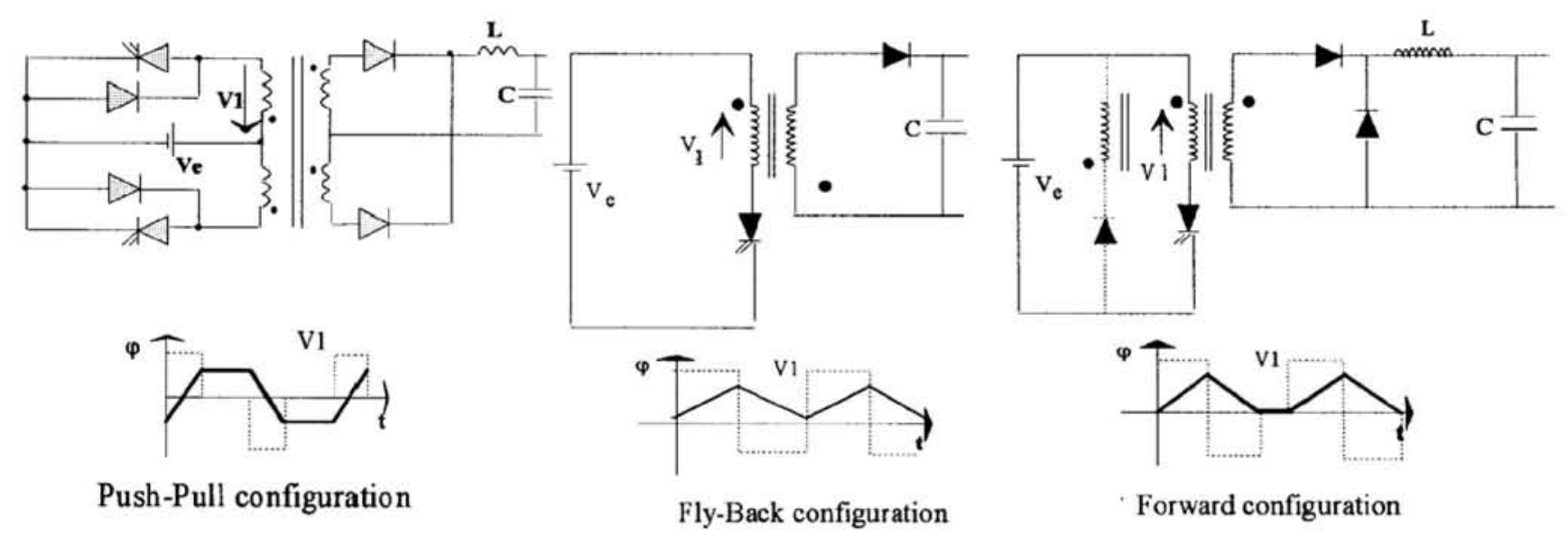

Fig. 5. Waveforms of the flux versus time according to the converter topology.
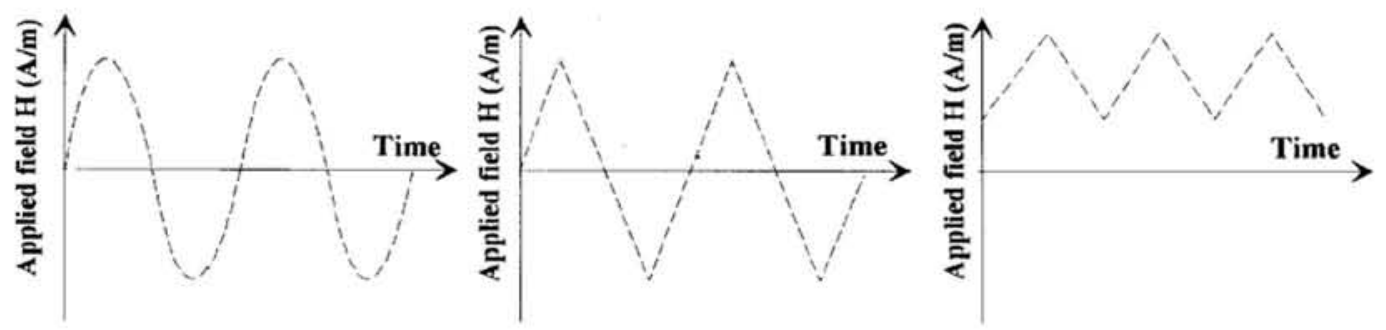

Fig. 6. Waveforms of the applied field $H$ versus time considered for our validation.

a model for a given material. $H(t)$ is the input of the model, and $B(t)$ and $d \varphi / d t$ represent the outputs. By integrating static and dynamic hysteresis loops, both static and total core losses are obtained.

\section{Dynamic Validation of the Model}

\section{A. Application Field and Choice of the Materials}

The field of application of soft ferrites is wide. It covers a frequency range between $10 \mathrm{kHz}$ and $1 \mathrm{MHz}$. According to the topology of the converter, flux density $B$ is symmetric or asymmetric, with magnitudes which are between $50-300 \mathrm{mT}$. Waveforms are rarely sinusoidal, but rather more triangular and trapezoidal as shown in Fig. 5. In Fig. 6, the three waveforms which have been chosen for our validation are presented: sinusoidal magnetic field $H$, triangular magnetic field $H$, and unipolar triangular magnetic field $H$ with a superimposed dc level. Except for the case of inductors, the flux is imposed by applying a voltage on the primary winding. For our validation, it is important to notice that we impose the field $H$ and not the flux. Nevertheless, we assume that chosen waveforms are sufficiently close to real operating conditions and that the model will be validated in the context of power electronics.

Experimental data is obtained with a magnetic component, which includes a primary winding of $n_{1}$ turns crossed by a current $I_{\mathrm{app}}(t)$. A secondary open winding of $n_{2}$ turns is also rounded in order to measure the voltage $U_{2}(t)$, which is equivalent of the derivative of the flux $\varphi$. A current generator provides the desired waveforms of the magnetic field $H$. Acquisition of data $I_{\text {app }}(t)$ and $U_{2}(t)$ is made by a TDS540 scope. Data are transferred to a calculator, and the voltage $U_{2}(t)$ is numerically integrated after an offset correction. The result of this integration gives the flux density $B$ as

$$
B=\frac{1}{n_{2} \cdot S_{e}} \cdot \int_{0}^{t} U_{2} \cdot d t .
$$

A noninductive shunt is used to measure the applied current $I_{\text {app }}(t)$. Current probes should not be used as erroneous measurements are observed with them. This is confirmed by a complete study made by Thottuvelil et al. [18]. The current generator provides current impulses which allow us to used high-value shunts and eliminates problems due to material heating.

The choice of materials must be sufficiently representative. Four of them have been chosen. Their usual application fields are given in Table I.

\section{B. Core Losses Prediction}

Core losses are predicted by integrating magnetic characteristics at the steady state. It is interesting to compare simulated losses versus experimental losses measured with a wattmeter. In order to quantify the performances of the model, we used an error criterion defined by

$$
\varepsilon=\left|\frac{\text { Experimental losses }- \text { Simulated losses }}{\text { Experimental losses }}\right| * 100 .
$$

Fig. 7 shows error criterion versus frequency. The applied field is sinusoidal. Frequencies are between $10-300 \mathrm{kHz}$. The 
TABLE I

Field of Application of the Soft Ferrites Retained for OUR Study. (Thomson-LCC Materials) Type of Material.

\begin{tabular}{c|c|c}
\hline Type of material & Usual frequency range & $\begin{array}{c}\text { Usual peak flux density } \\
\text { range }\end{array}$ \\
\hline B3 & $10 \mathrm{KHz}-50 \mathrm{KHz}$ & $200 \mathrm{mT}-300 \mathrm{mT}$ \\
\hline B4 & $10 \mathrm{KHz}-70 \mathrm{KHz}$ & $100 \mathrm{mT}-250 \mathrm{mT}$ \\
\hline B2 & $50 \mathrm{KHz}-250 \mathrm{KHz}$ & $100 \mathrm{mT}-200 \mathrm{mT}$ \\
\hline F2 & $100 \mathrm{KHz}-500 \mathrm{KHz}$ & $50 \mathrm{mT}-100 \mathrm{mT}$ \\
\hline
\end{tabular}

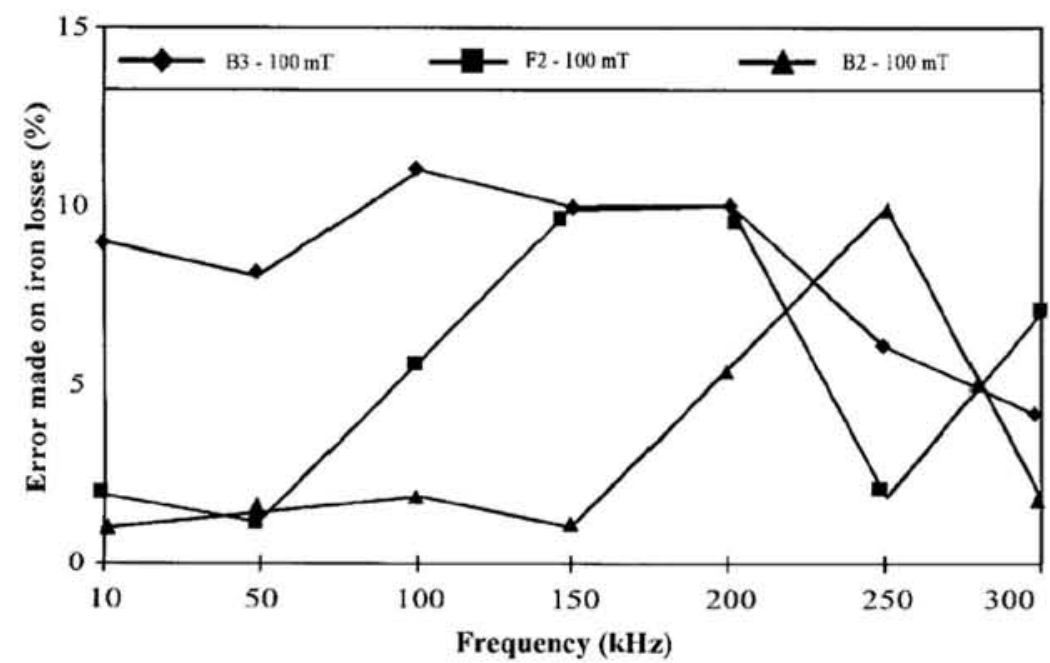

Fig. 7. Errors made on the predicted iron losses by the model for a sinusoidal magnetic field $H$ versus frequency. The magnitude of the flux density is equal to $100 \mathrm{mT}$.

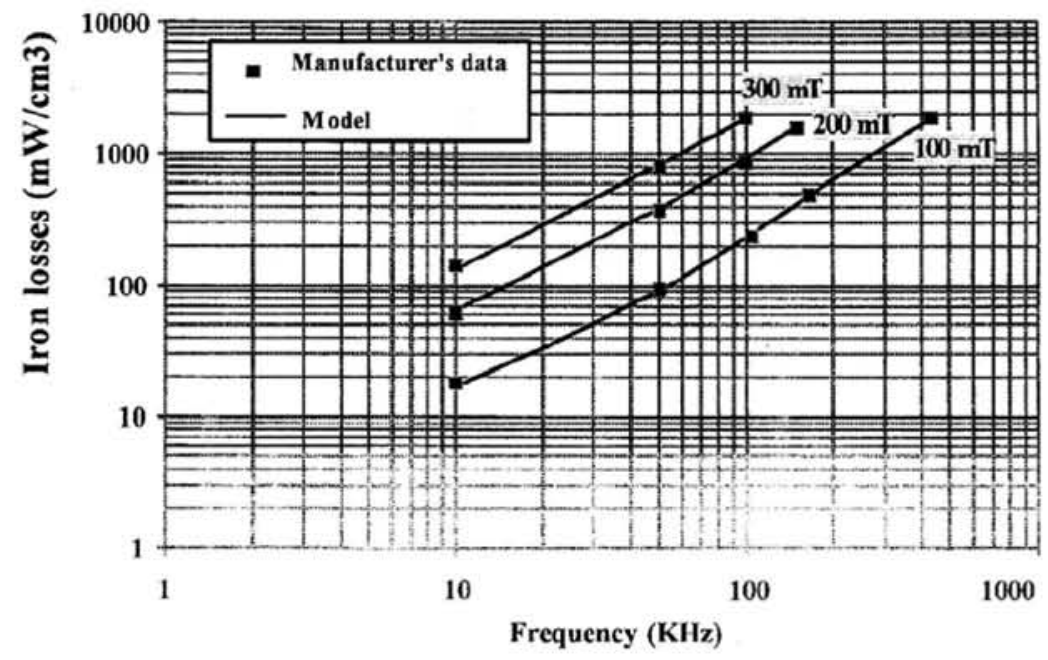

Fig. 8. Comparison between measured iron losses by manufacturer and simulated iron losses versus frequency.

magnitude of the peak flux density is equal to $100 \mathrm{mT}$, and three materials are considered. As one can see, iron losses are estimated accurately, generally with errors less than $10 \%$. With respect to manufacturer data, performances of the model are excellent too,
In Fig. 8, simulated and measured manufacturer core losses have been compared. Both static and dynamic effects are taken into account. At low frequencies, core losses are only due to hysteresis phenomena. When the frequency increases, dynamic effects occur and core losses depend on both hysteresis and 


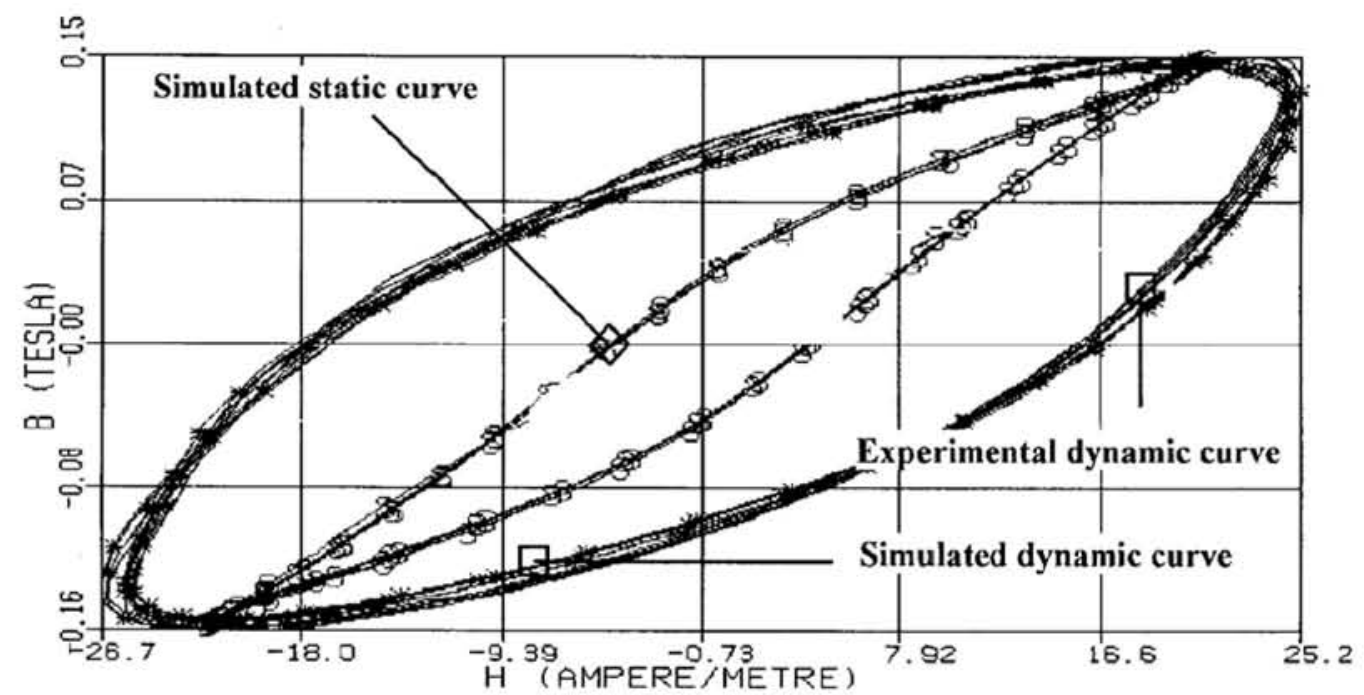

Fig. 9. Comparison between simulation and experiment. Triangular applied field of $160 \mathrm{kHz}$ and $25-\mathrm{A} / \mathrm{m}$ magnitude. $B 4$ material.

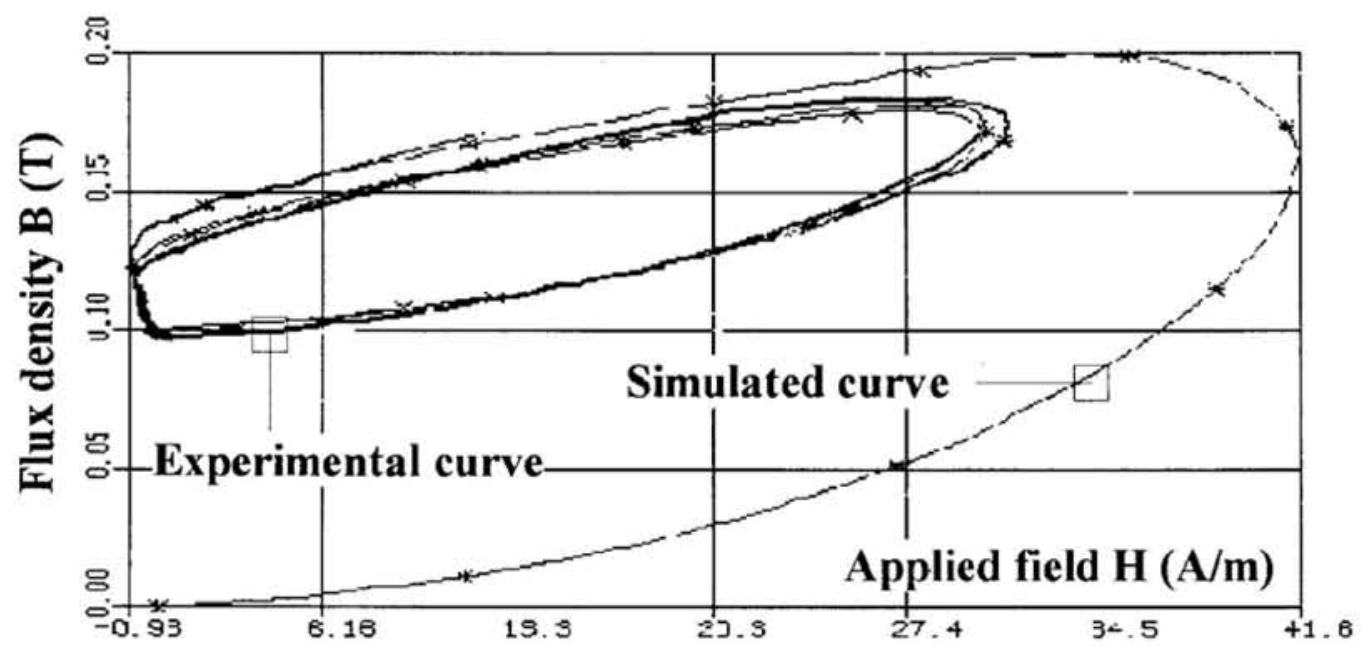

Fig. 10. Comparison between simulation and experiment. Rectified triangular magnetic field $H$ of $300-\mathrm{kHz}$ frequency and $42-\mathrm{A} / \mathrm{m}$ magnitude. $B 2 \mathrm{material}$.

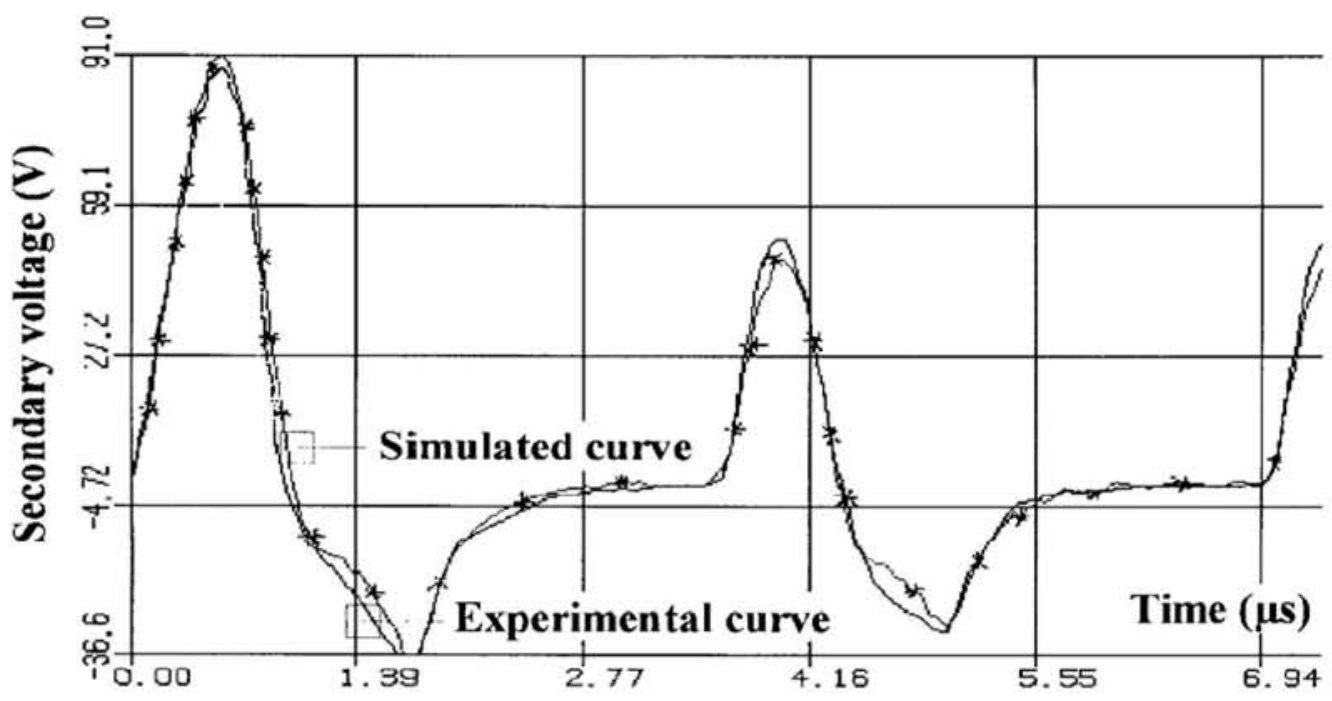

Fig. 11. Comparison between simulation and experiment. Rectified triangular magnetic field $H$ of $300-\mathrm{kHz}$ frequency and $42-\mathrm{A} / \mathrm{m}$ magnitude. $B 2$ material. 


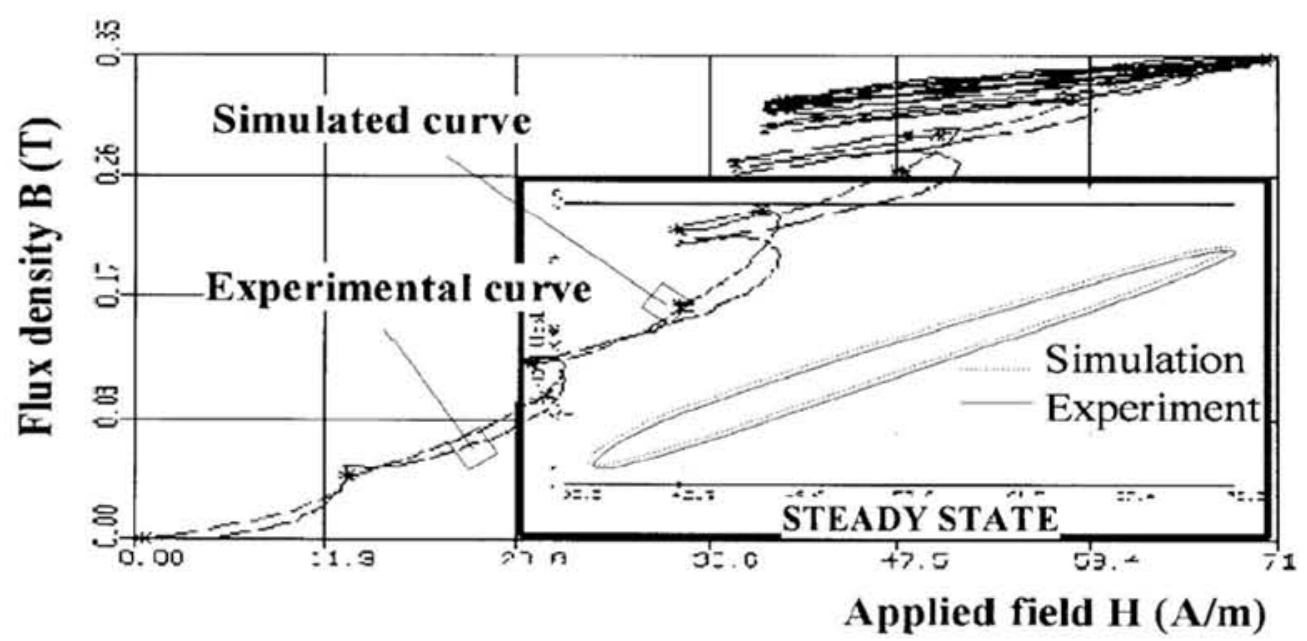

Fig. 12. Comparison between simulation and experiment for a rectified triangular applied field $H$ of $385-\mathrm{kHz}$ frequency with a transient state.

dynamic losses. One notes a very good accordance with errors less than $10 \%$. These results show that the model covers perfectly the application field of each material.

\section{Waveforms Prediction}

For the case of push-pull converters, magnetic characteristics obtained are symmetric. Fig. 9 presents a comparison between simulation and experiment. The presented magnetic characteristics have been obtained with a triangular magnetic field $H$ of $160-\mathrm{kHz}$ frequency and $25-\mathrm{A} / \mathrm{m}$ magnitude. The magnitude of the flux density $B$ is equal to $150 \mathrm{mT}$. In order to judge the importance of dynamic effects, we have superimposed the corresponding static curve. The considered magnetic material is the $B 4$ material, usually used at a frequency less than $70 \mathrm{kIIz}$. Core losses are larger to $1 \mathrm{~W} / \mathrm{cm}^{3}$. It is clear that this application does not correspond to a real application. But the proposed example illustrates perfectly the performances of the model which are not limited to the application field of each material. For this example, error made on the prediction of iron losses is equal to $5 \%$. Fig. 10 shows a comparison between simulation and experiment for a unipolar minor loop such as minor loops encountered in forward and fly-hack converters We have applied a rectified triangular field $H$ of a $300-\mathrm{kHz}$ frequency and $42-\mathrm{A} / \mathrm{m}$ magnitude. The magnitude of the flux density is equal to $200 \mathrm{mT}$. Here too, the behavior of the model is excellent. Error made on the prediction of iron losses is equal to $6 \%$. Globally, the model predicts iron losses with errors less than $15 \%$ for such applications. The derivative of the flux, corresponding to the previous magnetic characteristic presented, is well predicted too as shown in Fig. 11.

It is also important to control the behavior of the model for transient states. An improper account of transient states can give rise to bad results on the steady state. As one can see in Fig. 12, transient states are sufficiently well predicted to obtain very good results on the steady state.

\section{CONCLUSION}

A behavioral model of magnetic material has been presented. This model predicts $B(H), \varphi(t)$, and $d \varphi(t) / d t$ characteristics and iron losses. Initially developed for $\mathrm{FeSi}$ and $\mathrm{FeNi}$ material, this model has been improved in order to increase its performances for soft ferrites. The accuracy obtained on the prediction of waveforms is quite good, and, obviously, iron losses are predicted well too. Performances of the model are not limited to the steady state. Important transient states are taken into account too. The parameters of the model are easily identified, and this identification needs a few experimental data which are quickly and easily obtained. Simulation times require around $3 \mathrm{~s}$ with a PC486. This model constitutes an important advance in magnetic component modeling. Moreover, the next step concerns the implementation of the models in circuit simulation software.

\section{REFERENCES}

[1] J. J. Rousseau, J. P. Masson, and B. Lefebvre, "Behavioral model of iron losses," in Proc. IMACS, 1990.

[2] P. Tenant and J. J. Rousseau, "Dynamic model for soft ferrites," in Proc. PESC, Atlanta, GA, 1995, vol. 2.

[3] D. C. Jiles and D. L. Atherton, "Theory of ferromagnetic hysteresis," J. Magn. Mag. Mater., vol. 61, pp. 48-60, 1986.

[4] D. C. Jiles and B. Thoelke, "Theory of ferromagnetic hysteresis: Determination of model parameters from experimental hysteresis loop," IEEE Trans. Magn., vol. 25, pp. 3928-3930, 1989.

[5] F. Preisach, "Uber die magnetische nackwirkung," Zeitschrift für Physik, vol. 94 , pp. $277-302,1935$.

[6] I. D. Mayergoyz, Mathematical Models of Hysteresis. Berlin, Germany: Springer-Verlag, 1991.

[7] G. Biorci and D. Pescetti, "Analytical theory of the behavior of ferromagnetic materials," II Nuovo Cimento, vol. 7. pp. 829-281, 1958.

[8] S. Y. R. Hui and J. Zhu, "Magnetic hysteresis modeling and simulation using the Preisach theory and the TLM technique," IEEE Trans. Magn., vol. 5, pp. 837-842, 1994.

[9] G. Kadar, "On the Preisach function of ferromagnetic hysteresis," $J$. Appl. Phys., vol. 61 , no. 8, pp. 4013-4015, 1987.

[10] O. Benda, "To the question of the reversible processes in the Preisach model," Elect. Eng. J. Slovak Academy Sci., vol. 3, 1991.

[11] G. Kadar, E. Kisdi-Koszo, L. Potocky, P. J. Safarik, and E. D. Torre, "Bilinear product Preisach modeling of magnetic hysteresis curves," IEEE Trans. Magn., vol. 25, pp. 3931-3933, 1989. 
[12] E. D. Torre and F. Vajda, "Parameter identification of the completemoving hysteresis model using major loop data," IEEE Trans. Magn., vol. 30 , pp. $4987-5000,1994$.

[13] D. L. Atherton, B. Szpunar, and J. A. Szpunar, "A new approach to Preisach diagrams," IEEE Trans. Magn., vol. 23, pp. 1856-1865, 1987.

[14] G. Kadar and E. D. Torre, "Determination of the bilinear product Preisach function," J. Appl. Phys, vol, 63, pp. 3001-3003, 1988.

[15] E. D. Torre, J. Oti, and G. Kadar, "Preisach modeling and reversible magnetization," IEEE Trans. Magn., vol. 26, pp. 3052-3058, 1990.

[16] F. Vajda, E. D. Torre, and M. Pardavi-Horvath, "Analysis of reversible magnetization-dependent Preisach models for recording media," J. Magn. Mag. Mater, vol. 115, pp. 187-189, 1992.

[17] F. Vajda and E. D. Torre, "Efficient numerical implementation of complete moving hysteresis model," IEEE Trans. Magn., vol. 29, pp. $1532-1537,1993$.

[18] V. J. Thottuvelil, T. G. Wilson, and H. A. Owen, "High frequency measurement techniques for magnetic cores," IEEE Trans. Magn., vol. 5, pp. 41-53, 1990.

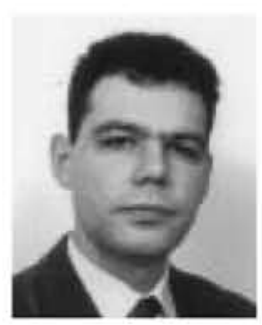

P. Tenant was born in 1966 . He received the $\mathrm{Ph}$.D. degree from the Institut National des Sciences Appliques (INSA), Lyon, France, in 1995.

$\mathrm{He}$ was with Cegely from 1991 to 1995. His research interest is magnetic phenomena modeling. Since 1996, he has been wilh ISOLSEC, Villeurbanne, Cedex, France, and currently works on the design of transformers.

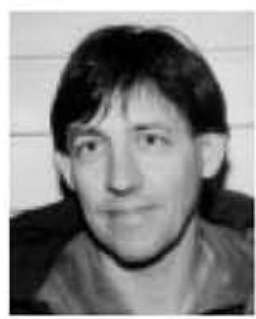

J. J. Rousseau was born in 1953 . He received the Eng. degree in 1979 and the Ph.D. degree in electrical engineering in 1983, both from the University of Clermont-Ferrand, Clermont-Ferrand, France.

$\mathrm{He}$ is currently an Associate Professor at both the Institut National des Sciences Appliques (INSA), Lyon, France, and Institut Universitairede Technologie (IUT), St. Etienne, France. He has been with the Cegely Electrical Engineering Center, Lyon, since 1987. His current research interests are power electronics and magnetic component modeling. 